\title{
Self-directed use of mobile devices for language learning beyond the classroom
}

\author{
CHUN LAI \\ The University of Hong Kong, Hong Kong \\ (email: laichun@hku.hk) \\ DONGPING ZHENG \\ University of Hawaii, USA \\ Guangdong University of Foreign Studies, China \\ Jilin Huaqiao University of Foreign Languages, China \\ (email: zhengd@hawaii.edu)
}

\begin{abstract}
The essence of mobile learning is learners' agentic use of mobile devices to create learning experiences across time and space. Thus, understanding learners' perceptions and preferred use of mobile devices for learning are critical to realizing the educational potentials of mobile learning. This study explored language learners' self-directed use of mobile devices beyond the classroom through a survey and interview study with foreign language learners at a university in Hong Kong. A total of 256 learners were surveyed and 18 were interviewed to understand the nature of mobile language learning experiences that these learners engaged in autonomously beyond the classroom. Exploratory factor analysis yielded three dimensions of self-directed out-of-class mobile learning experience. Among the three dimensions, learners were found to use mobile devices more for facilitating the personalization of learning than for enhancing the authenticity and social connection in learning. This study further revealed that selective use was an outcome of the interaction between learner-defined affordances of the devices, their culturally informed and habitual use of the devices, their perceptions of the nature of the learning tasks, and the tempo-spatial circumstances of task implementation. The findings suggest that these factors need to be considered when designing mobile learning activities and educational interventions that promote mobile learning beyond the classroom.
\end{abstract}

Keywords: informal language learning, mobile learning

\section{Introduction}

Mobile learning has been widely acclaimed for its revolutionary and liberating redefinition of learning in which, with the assistance of mobile devices, learners are given increased mobility to create "impromptu sites of learning" and personalized learning ecologies (Bachmair \& Pachler, 2014; Kukulska-Hulme, Gaved, Jones, Norris \& Peasgood, 2017; Kukulska-Hulme \& Sharples, 2016; Wong, Milrad \& Specht, 2015). The conceptualized 
mobile learning culture rests essentially on learner agency and ability to utilize the enhanced mobility to construct learning experiences across time and space (Burston, 2014a; Kukulska-Hulme, 2012; Underwood, Luckin \& Winters, 2014). Mobile learning entails not only the mobility of technology but also more importantly the mobility of time, space, and learning experience. Thus, learners are at the center of mobile learning, and facilitating mobile learning cannot do without an in-depth understanding of learners' perspectives, especially their perspectives of mobile learning in informal learning contexts (Byrne \& Diem, 2014; Ch'ng \& Samsudin, 2013; Kukulska-Hulme, 2012). An understanding of learners' perceptions and preferred use of mobile devices for learning beyond the classroom is critical to achieving "the possible synchronicity" of the designed mobile learning experience and learner-valued practices (Kukulska-Hulme, 2012: 3). And such an understanding also informs educators on how they could support learners to create agentic mobile learning experiences across time and place (Stockwell \& Hubbard, 2013).

However, the majority of the research studies on mobile-assisted language learning have been lab and classroom trials or experiments of mobile applications in the formal educational contexts (Burston, 2015; Demouy, Jones, Kan, Kukulska-Hulme \& Eardley, 2016; Duman, Orhon \& Gedik, 2015; Kukulska-Hulme, 2016; Ma, 2016). Only recently did we witness an increasing research interest in understanding learners' use of mobile devices beyond the classroom (Jones, 2015; Kukulska-Hulme et al., 2017; Viberg \& Grönlund, 2013; White \& Mills, 2014). Thus, mobile learning in informal language learning contexts is a "less explored territory to date in the field of MALL" (Kukulska-Hulme, 2016: 138). However, a recent meta-analysis study on mobile learning in general found that mobile learning had a higher effect size in informal settings than in formal settings (Sung, Chang \& Liu, 2016). Thus, insights into the learning experience in this territory are much needed in order to maximize the educational potentials of mobile learning (Burston, 2015; Sharples \& Pea, 2014). Given the importance of mobile learning in informal settings and the limited research efforts in documenting learners' self-directed mobile language learning practices beyond the classroom, this study aimed at filling in this research gap by shedding light on the nature of university foreign language learners' agentic mobile language learning experience beyond the classroom.

\section{Literature review}

Various studies have examined language learners' perceptions of and voluntary interactions with mobile devices out of class in pedagogically designed learning interventions (Bradley, Lindström \& Hashemi, 2017; Petersen, Procter-Legg \& Cacchione, 2014; Pollara \& Broussard, 2011; Wang \& Smith, 2013). These studies have found that learners were in general positive towards mobile learning, but exhibited some reservations in their actual use and expressed concerns over the lack of immediate support in such informal learning contexts (Kim, Ilon \& Altmann, 2013; Liu, Kuo, Shi \& Chen, 2015; Stockwell, 2010; Waragai, Raindl, Ohta \& Miyasaka, 2016). It was also found that students used the prescribed apps primarily during working hours and working days, and equally in both public and private places (Castrillo, Martín Monje \& Bárcena, 2014; Read, Bárcena \& Kukulska-Hulme, 2016). Researchers also found that when providing a choice of digital tools to access the learning systems, learners preferred computers to mobile devices (Liu et al., 2015; Stockwell, 2008, 2013). 
In addition to these reports on teacher-initiated, self-directed mobile language learning beyond the classroom, there have also been a few studies that examined learners' self-initiated, self-directed out-of-class mobile language learning experience (Jones, 2015; Kukulska-Hulme \& de los Arcos, 2011; Steel, 2012; Viberg \& Grönlund, 2013; White \& Mills, 2014). Learners have been found to hold positive views towards the value of mobile devices for language learning (Hsu, 2013; Rahamat, Shah, Din \& Aziz, 2011; Viberg \& Grönlund, 2013; White \& Mills, 2014), perceiving mobile devices more positively for supporting ubiquitous multimedia language learning but less positively for enhancing collaboration and social connectivity in language learning (Chen, 2013; Dashtestani, 2016; Kukulska-Hulme \& de los Arcos, 2011; Steel, 2015; Viberg \& Grönlund, 2013). Their motives for using mobile devices for language learning are to fill in the gaps in their daily schedules and utilize "pockets of time" (Steel, 2012: 3; see also Jones, 2015), and to explore language learning potentials of the tools they regularly use for daily life purposes (Demouy et al., 2016). In terms of their actual use of mobile devices for language learning, learners are found to engage in a variety of activities with mobile devices outside the classroom, ranging from language drill and practice to authentic communication. Listening to audio and watching videos are found to be the most common activity types, followed by grammar and vocabulary practices, and reading (Bradley et al., 2017; Demouy et al., 2016; Jones, 2015; Kukulska-Hulme \& de los Arcos, 2011; Viberg \& Grönlund, 2013). And learners have been found to diverge in their use of mobile devices for social communication (Ma, 2016; Steel, 2012). Despite the different types of activities learners engage in, mobile learning outside the classroom was perceived to benefit vocabulary learning the most (Steel, 2015).

Thus, current literature has yielded some insights into language learners' selective use of mobile resources and their perceptions of the values of mobile devices for different aspects of language learning in out-of-class contexts. However, these initial explorations into self-directed mobile language learning beyond the classroom could not reveal much on the types of mobile learning experience that language learners engage in. There are a few conceptual frameworks that delineate the different dimensions of mobile learning. For instance, Kearney, Schuck, Burden and Aubusson (2012) conceptualized an influential pedagogical framework of mobile learning, which highlights three core features of m-learning: (1) personalization in terms of learner agency in learning and ownership of learning; (2) authenticity in respect to contextualized and realistic learning tasks and in situ practices; and (3) collaboration that refers to data sharing, communication, and connected learning across time and space. Focusing specifically on language learning, Sung, Chang and Yang (2015) summarized four aspects of literature-suggested applications of mobile devices in language learning: (1) mobility and portability that facilitate learning anytime and anywhere and support new teaching and learning styles; (2) social connectivity/interaction, where learners share, collaborate, and communicate with others; (3) context sensitivity in terms of collecting time- and context-dependent data and connect learning across settings; and (4) individuality that enables customized and personalized learning experience. These frameworks of mobile learning were proposed with regard to the use of mobile devices in the contexts of formal learning; whether the same dimensions of mobile learning apply and how the dimensions are manifested in informal learning contexts are empirical questions that await investigation. This study aimed at enriching our understanding of this issue by examining the nature of self-directed mobile 
language learning in out-of-class learning contexts. Specifically, it focused on two research questions:

1. What are the different dimensions of learners' self-initiated, self-directed out-of-class language learning with mobile devices?

2. How do language learners utilize different technological tools to construct self-directed out-of-class mobile learning experiences?

\section{Research method}

\subsection{Participants}

Undergraduate students who were taking foreign language courses from a comprehensive research university in Hong Kong were recruited for the study. Hong Kong has a high profile of smartphone usage: smartphone ownership is 77\% (Hong Kong Census and Statistics Department, 2016), and over 90\% of Hong Kong students possess smartphones, with nearly half spending over 3 hours on their smartphones per day (Hong Kong Computer Society, 2013). The current study was announced through mass emails from course coordinators of foreign language departments or through online announcements on course Moodle sites. A total of 276 foreign language learners completed the online survey. After discarding the incomplete questionnaires, a data set of 256 valid survey responses remained. The survey participants averaged 20 years old, and $45 \%$ of them were freshmen. They were of Chinese ethnic background and $77 \%$ of them were female. The participants were studying different foreign languages, including Japanese, Spanish, German, Korean, French, and Portuguese. Forty-eight percent of the participants had studied the language for less than one year, and $41 \%$ of them had one to four years of learning experience. Sixty-four percent of the participants self-rated themselves as of beginning proficiency level, and only $4 \%$ rated themselves as of advanced level.

Among the participants who signed up for the follow-up interview, 18 were randomly selected to join the interview. Fourteen out of the 18 interview participants were female. They were studying a wide range of foreign languages. Ten of them had studied the language for one year.

\subsection{Data collection}

A questionnaire was constructed to collect students' account of the nature, frequency, and tool selection of their engagement in self-directed mobile learning outside the classroom. The participants were given the following statement before they could commence with the survey: "We are interested in your self-initiated, self-directed language learning outside your language classroom (other than completing your teacher-assigned work)". Both learners' uses of mobile devices for intentional learning and for incidental learning were elicited in this study, where the participants were asked to report on their use of "mobile devices in the target language or to support learning of the target language outside the classroom". Eighteen items related to different aspects of self-directed out-of-class use of mobile devices for language learning were constructed in reference to current conceptualization of the affordances of mobile devices for learning (Burston, 2014b; Kearney et al., 2012; Stockwell \& Hubbard, 2013; Sung et al., 2015). Students were asked to indicate their agreement with these different aspects of mobile learning on a 6-point Likert scale (1 indicating "strongly 
disagree" and 6 indicating "strongly agree"), and to report on the average hours per week they engaged in these different aspects of mobile learning outside the language classroom on another 6-point Likert scale (1 indicating "never", 2 indicating "less than 1 hour", 3 indicating " $1-3$ hours [ $<3$ hrs]", 4 indicating " $3-7$ hours $[<7 \mathrm{hrs}]$ ", 5 indicating "7-14 hours [ $<14 \mathrm{hrs}]$ ", and 6 indicating " 14 and more than 14 hours"). The same 6-point Likert scale was used to elicit the frequency of their use of mobile devices to engage in different types of self-initiated learning activities (class-related and non-class-related) and for the development of different language skills. In addition, students' perception of the value of mobile devices in supporting the different aspects of mobile learning was also elicited using 6-point Likert scale items (1 being "strongly disagree" and 6 being "strongly agree"). Moreover, the questionnaire also elicited the participants' account on their selective use of different mobile devices (mobile phones, tablets, and laptops) when engaging in various technology-enhanced activities in the target language outside the classroom. Demographic data (e.g. gender, age, years of language study, etc.) were also collected. The questionnaire items were pilot tested and revised in several iterations with language learners at the university where the study was conducted. The final questionnaire was administered online close to the end of the school semester.

A semi-structured interview was also constructed to tap deeper into the participants' use of mobile devices for different language learning experiences. Prior to the one-on-one individual interview, each participant was asked to jot down on a piece of paper the out-ofclass activities they engaged in in the target language, or, for the learning of the language, that involved the use of technology and the devices they usually used for such activities. The notes were then used as a stimulus for the interview, and the participants were asked to elaborate on how they engaged in each activity and why they chose the specific digital device(s) for the experience. They were also asked about the reasons for not engaging in some mobile learning experiences discussed in the existing literature. The interviews were conducted in either English or Chinese, depending on the interviewees' preferences. Each interview lasted around 30 minutes. The interviewees were given minimal guidance during the interview, and only elaboration and clarification questions were asked to elicit in-depth responses and confirm the intended meaning by the participants.

\subsection{Data analysis}

An exploratory factor analysis was conducted on the items that elicited the nature of the participants' self-reported use of mobile devices for language learning beyond the classroom. Principal axis factor analysis was used as the extraction technique, with promax as the rotation method. Two items that had lower than 0.40 loading on all the three factors were deleted (Hair, Black, Babin, Anderson \& Tatham, 1998; Stevens, 1992). Scree plot and minimum eigenvalue of 1 were used to decide the cut-off value for extraction. Descriptive statistical analyses were conducted on the questionnaire items retained in the factor model to reveal learners' engagement in different types of mobile-assisted out-of-class language learning experiences.

The interview responses were transcribed word for word in either English or Chinese. The data were analyzed inductively through a cyclical and evolving process of coding and recoding (Saldaña, 2016). For each interview transcript, segments of interview responses on different technological experiences were first identified, and the segment on each 
technological experience was further divided into sub-segments concerning different aspects of the engagement (when and where they engaged in the experience, how they interacted with the technological resources, which tool[s] were utilized in the experience, and reasons for their selective engagement). In vivo coding was used to capture the nature of learner engagement in the technological experience, and pattern coding was then used to aggregate similar codes into analytic categories (e.g. in vivo codes like "I can use it everywhere", "use it for the whole day", "instant searching", and "quick reply" were categorized into first-order analytical categories "no time and space boundary" and "immediate access", respectively, which were aggregated into a second-order analytic category "affordances of mobile devices"). The initial coding of analytic categories was then compared across interviewees to find repeating ideas to saturate categories with repeated supporting evidence and for cross validation of the categories that emerged.

\section{Findings}

\subsection{Characteristics of out-of-class language learning with mobile devices}

The survey responses showed that the participants were actively utilizing mobile devices to support their language learning beyond the classroom, spending an average of 1-3 hours per week (see Table 1). They reported similar frequencies of mobile use for reviewing and strengthening what was learned in class and for expanding exposure to and use of the target language. Their interview responses revealed frequent use of mobile dictionary, Google Translate, and Google search engine to assist with homework, and the use of language learning apps or photo-captured texts or vocabulary lists from the textbook during transit. Watching videos, listening to songs, and browsing Facebook or Instagram updates on the go also appeared frequently in their interview accounts.

The participants reported using mobile devices to support vocabulary learning the most. Quite a portion of mobile-assisted vocabulary learning came from word referencing for comprehension or production. Playing vocabulary games or memorizing vocabulary lists on the Mass Transit Railway (MTR) were also sources of vocabulary learning. Quite a few participants reported sophisticated use of multiple reference sources for triangulation during word search (e.g. using Google Translate to get a quick idea of the meaning, which was often followed up with Google search engine to obtain an in-depth understanding of the contexts of use).

The participants also reported greater frequency of using mobile devices to develop receptive skills (see Table 2). The only cases of productive use were posting on social networking sites or chatting with friends or classmates on instant messengers, such as

Table 1. Use of mobile devices for language learning outside the classroom $(N=256)$

\begin{tabular}{llr}
\hline \hline & $M$ & $S D$ \\
\hline \hline Self-initiated use for reviewing and strengthening coursework & 2.79 & 1.07 \\
Self-initiated use for expanding access to the target language & 2.76 & 1.18 \\
\hline \hline
\end{tabular}

Note. The value was based on a 6-point Likert scale, with 2 being less than 1 hour per week and 3 being 1-3 hours per week. 
Table 2. Use of mobile devices for different language aspects $(N=256)$

\begin{tabular}{lll}
\hline \hline & $M$ & $S D$ \\
\hline \hline Vocabulary & 3.24 & 1.16 \\
Grammar & 2.79 & 1.23 \\
Culture & 2.87 & 1.21 \\
Listening & 2.93 & 1.27 \\
Reading & 2.88 & 1.21 \\
Writing & 2.50 & 1.27 \\
Speaking & 2.15 & 1.11 \\
\hline \hline
\end{tabular}

Note. The value was based on a 6-point Likert scale, with 2 being less than 1 hour per week, 3 being 1-3 hours per week, and 4 being 3-7 hours per week.

WhatsApp. However, such cases were not very frequent as the participants reported using social networking sites more for reading. The written mode of communication was preferred over the oral mode because it "gave more time to arrange what to say". The participants were also very careful with their written outputs. For instance, one interview participant remarked: "I checked the dictionary when I used Spanish to comment on others' posts to make sure I wouldn't make any mistake, because the comments were publicly displayed to my friends and the friends of those friends". And another commented: "when I was texting in French, I had to check to see whether I had missed something or whether it was an appropriate way of expression. I hated to send hastily and would try to catch and correct mistakes myself before others pointing out those mistakes for me".

\subsection{Dimensions of out-of-class language learning with mobile devices}

The factor analysis yielded three factors that could explain $62.2 \%$ of the variance in learners' out-of-class mobile learning experience. The three factors included (1) personalization, where learners used mobile devices to engage in and assist autonomous, customized learning anytime and anywhere; (2) authenticity, where learners used mobile devices to engage in authentic learning experience; and (3) connectivity, where learners used mobile devices to connect with native speakers of the target language and peer learners (see Table 3). The participants reported most positively on the use of mobile devices for personalization $(M=4.89, S D=0.71)$. However, the participants reported less positively on the use of mobile devices to engage in authentic language learning experience $(M=4.04, S D=0.90)$ and to enhance connection with others in the target language $(M=4.07, S D=0.96)$.

Among the 175 survey participants who gave detailed responses to the open-ended question that elicited examples of their mobile language learning, $131(75 \%)$ mentioned using mobile devices to either provide instant help on language study and language use or to study and use the language at any time and any place. Only 66 (38\%) participants mentioned using mobile devices to access authentic language, such as to listen to songs, watch videos or drama, browse news or blogs, and view Facebook or Twitter updates. Even fewer participants $(n=21,12 \%)$ mentioned using mobile devices to communicate with others in the target language. Correspondingly, when responding to the frequency of engagement in 
Table 3. Different types of mobile-assisted language learning experience $(N=256)$

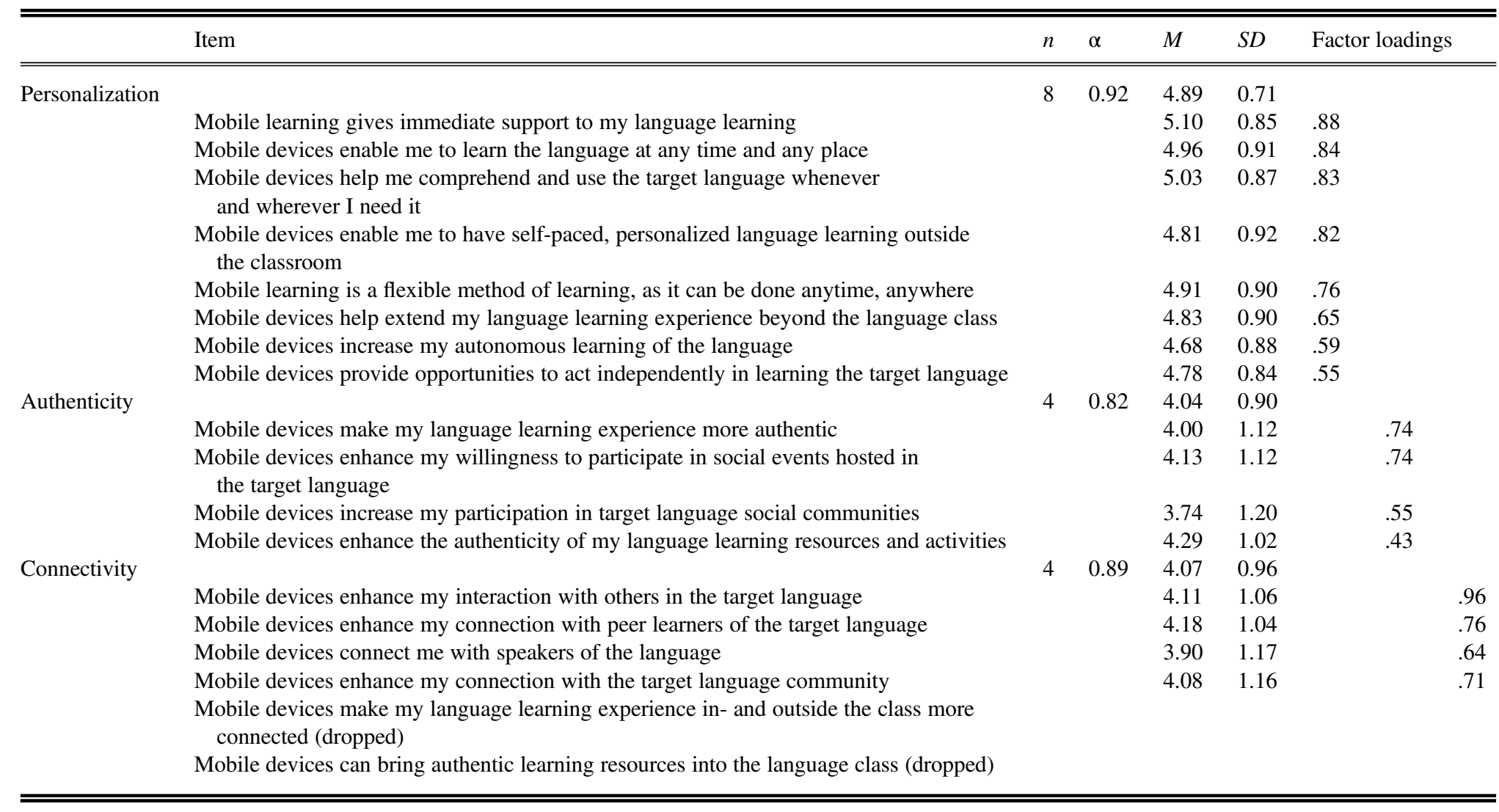

connected (dropped) 
Table 4. Frequency of different mobile-assisted language learning experience

\begin{tabular}{llc}
\hline \hline & $M$ & $S D$ \\
\hline \hline Personalization & 2.60 & 1.03 \\
Authenticity & 2.38 & 1.24 \\
Connectivity & 2.35 & 1.23 \\
\hline \hline
\end{tabular}

Note. The items were rated on a 6-point Likert scale, with 2 being less than 1 hour per week and 3 being $1-3$ hours $(<3)$ per week.

Table 5. Learner perception of the usefulness of mobile devices for different language learning experience

\begin{tabular}{llc}
\hline \hline & $M$ & $S D$ \\
\hline \hline Personalization & 5.03 & 0.66 \\
Authenticity & 4.38 & 0.85 \\
Connectivity & 4.34 & 1.01 \\
\hline \hline
\end{tabular}

Note. The items were evaluated on a 6-point Likert scale, with 4 being a little bit useful, 5 being useful, and 6 being very useful.

different learning experiences, the participants reported a higher frequency of using mobile devices to support personalized learning than to facilitate authentic learning experience and communication in the target language (see Table 4).

One reason behind the different frequencies of engagement was reflected in the participants' perception of the usefulness of mobile devices in facilitating different learning experiences (see Table 5). The survey participants perceived mobile devices as most useful in supporting personalized learning $(M=5.03, S D=0.66)$.

The view in favor of personalized learning was also echoed in the participants' interview responses. The participants reported that mobile devices had two primary affordances for language learning: (1) extending learning across time and space, and (2) providing instant help. Two thirds of the interview participants felt that mobile devices extended language learning (e.g. "If I don't have those mobile devices, I think I wouldn't spend that much time learning Japanese"). The extended learning came from anytime and anywhere access to materials in the target language. One participant remarked, "I can use it [mobile phone] everywhere. Even when I'm walking, I converse with my friends in Korean". Another participant commented: "It takes one hour to travel between home and university, and during this one hour I can use my mobile to learn German". And a learner of Japanese shared that she "loved watching Japanese drama. Whenever [she] had time, [she] just grabbed mobile devices to watch Japanese drama". More than half of the interview participants also remarked that mobile devices contributed to language learning through providing instant assistance during study and language use. They talked about how mobile devices provided immediate help on the new vocabularies and slangs they encountered in class and freed them from the embarrassment of seeking teachers' help in front of classmates, and how mobile devices resolved communication breakdowns for them in a fast 
and convenient fashion. In contrast, only a small portion of the participants identified enhanced authenticity and communication as the contributions of mobile devices for language learning. Five participants remarked on enhanced authenticity of language learning experience via mobile devices (e.g. "a better experience of real Japanese learning", "information that couldn't be accessed in class", and "the language in daily life"), and only one interview participant reported that the affordance of mobile devices was to enhance online communication with others.

The participants further expressed concerns about the inadequacy of communication in a second language in fulfilling the networking functions of social communication, which was listed as another reason behind their limited use of mobile devices for social connections. More than half of the interview participants mentioned not using mobile devices to engage in social networking in the target language because their existent social circles were in their native languages, and posting updates in a language that was strange to the existent social circles would disrupt existing social relationships. For instance, one participant said that if she typed Spanish on her Facebook updates, "not many friends would know what [she] was saying. It would be meaningless". Another participant decided not to post in Japanese because she felt that if she used "too much Japanese in Facebook, it's like showing off". Yet another participant chose not to post Spanish to his Instagram account because doing so would not bring about any social interaction: "most of my friends don't know Spanish. So they won't like some pages with Spanish stuff". The participants also expressed being more comfortable talking about personal life in their mother tongues. For instance, one learner of Japanese said: "If I have to talk about my personal life, I prefer posting things in Cantonese rather than in Japanese". A learner of Spanish remarked that it was troublesome to check dictionaries constantly to sustain conversations in the target language and thus she preferred communicating in English and Chinese, which were more native to her.

Moreover, the participants mentioned several reasons that were unique to the technological affordances of mobile devices. The limitations of mobile devices, such as small screens and slow connections, kept the participants from capitalizing on the potentials of mobile devices for enhancing the authenticity of learning resources. The participants reported that it was "tiring" to watch videos, read long passages, and listen to songs while watching lyrics on mobile devices and that it was "very difficult to concentrate for a long time" on mobile devices. Several participants also reported that they did not utilize the photo capture function of mobile devices to collect real-life artifacts in the target language for follow-up consultation with teachers because mobile devices afforded another more convenient and faster function: instant online checking. As one participant commented, "most questions can be answered on the Internet. So I don't need to get help from the others".

\subsection{Tool selection for out-of-class language learning}

Given the potential constraints of mobile devices, we also asked the survey participants to report the digital devices they primarily used for different language learning activities. It was found that tablets, such as the iPad, were not frequently used for language learning. In the personalized learning dimension, around $60-70 \%$ of the participants primarily used mobile phones to seek instant help for comprehension and language use, whereas they used mobile phones and laptops equally for vocabulary and grammar study using quizzes and flashcards. In the authenticity dimension, a greater percentage of the participants reported primarily using 
laptops for surfing online and watching videos. They were equally likely to choose mobile phones and laptops for listening and casual reading. In the connectivity dimension, the participants reported a predominant preference for mobile phones (see Table 6).

The participants' selective use of tools for different dimensions of learning experiences is related to their positioning of these tools in their life. The participants perceived close connections between mobile phones and daily life, but tended to associate laptops with serious study, which were reflected in the following interview quotes: "I usually use the laptop for study and the mobile for entertainment"; "when chatting with friends for entertainment, I just use the mobile phone"; and "I have this perception that the mobile phone is for leisure and the computer is for formal work". One learner of Japanese elaborated: "I feel mobile devices are more related to my daily life. I don't take a laptop on the MTR. I access my mobile devices whenever I want". Another participant remarked: "I would say, on the laptop I'm more motivated to learn, but on the mobile, I'm just killing time". Because of the perceived link of laptops with serious study, the participants reported using mobile phones more for social communication. For instance, one participant recounted why he never used Facebook on his laptop: "when I use the laptop, I really want to do something serious. So when I turn on Facebook, I would have this guilty feeling of wasting time". To him, using Facebook on the mobile phone was natural because "using the mobile phone means I have some time to kill". The participants' interview responses indicated that the perceived association of mobile phones with leisure and laptops with learning had something to do with the different levels of concentration each device affords. According to them, the level of concentration afforded by different devices was influenced by their screen sizes ("when the screen is larger, I feel more concentrated"), and by the levels of distraction embedded in the devices ("when I use mobile phone, I have to switch off the Wi-Fi in order not to be disturbed by WhatsApp"). The level of concentration was also influenced by the locations where the digital devices were normally used. The participants reported using mobile phones anytime and anyplace but using laptops in fixed places such as at home, which led to the differences in the level of concentration when they were using these two devices. For instance, one participant said: "I usually use my laptop at home and it is quieter. When using my phone, I am usually somewhere outside my home where it is noisier and has more distractions". The association of mobile phones with daily life explained why the participants predominantly used mobile phones for connectivity.

The close association of mobile phones with daily life entertainment made it potentially supportive of the authenticity dimension of the learning experience, which, however, was not backed up by the survey participants' responses. The survey participants reported selecting laptops equally or, in some cases, even more frequently for activities that enhanced the authenticity of their learning experience. One reason was that learners may approach these authentic materials either as entertainment or as sources for serious study. This point was exemplified in the following quote: "when I was exploring new songs that I had never heard before and I needed to learn the words in the song, I would use the laptop because I needed to read the lyrics, jot down the words and search the dictionaries for meanings. When I was listening to songs I already knew, I used the mobile phone". The participants also frequently cited larger screens and better connections as reasons behind their preference for using laptops to watch movies and TV shows and read long texts.

The interview responses further revealed that the participants used mobile devices for tasks that were simpler and of short duration. In contrast, the participants chose laptops for 
Table 6. Primary digital devices for different out-of-class language learning activities

\begin{tabular}{|c|c|c|c|c|c|}
\hline & & Items & Mobile phone & Tablets & Laptop \\
\hline \multirow[t]{4}{*}{ Personalization } & Consulting dictionary or translation tools & to facilitate comprehension and language use on the go & $73.4 \%$ & $4.6 \%$ & $22 \%$ \\
\hline & & $\begin{array}{l}\text { to facilitate comprehension and language use } \\
\text { during self-study }\end{array}$ & $63.5 \%$ & $5.9 \%$ & $30.6 \%$ \\
\hline & $\begin{array}{l}\text { Studying vocabulary and grammar of the } \\
\text { target language }\end{array}$ & using vocabulary/grammar quizzes & $40.2 \%$ & $10 \%$ & $49.8 \%$ \\
\hline & & using flashcards & $50.9 \%$ & $10.7 \%$ & $38.4 \%$ \\
\hline \multirow{7}{*}{ Authenticity } & Listening and reading & Listening to audio files & $41.9 \%$ & $8.6 \%$ & $49.5 \%$ \\
\hline & & Reading e-news, e-books, or novels written & $40.2 \%$ & $13.7 \%$ & $46.1 \%$ \\
\hline & Searching online information & in the target language & $30.1 \%$ & $7.8 \%$ & $62.1 \%$ \\
\hline & & related to the target language or the target culture & $32.9 \%$ & $7.7 \%$ & $59.5 \%$ \\
\hline & Watching videos & Watching video clips & $26.6 \%$ & $12.6 \%$ & $60.8 \%$ \\
\hline & & Watching TV shows or movies & $20.7 \%$ & $11.7 \%$ & $67.6 \%$ \\
\hline & Playing games & Playing games & $52.7 \%$ & $10.8 \%$ & $36.5 \%$ \\
\hline \multirow[t]{4}{*}{ Connectivity } & Text messaging & Text messaging or instant messaging & $83 \%$ & $4.9 \%$ & $12.1 \%$ \\
\hline & Emailing & Emailing & $28.3 \%$ & $6.2 \%$ & $65.5 \%$ \\
\hline & Social networking & Sharing contents & $68.9 \%$ & $4.5 \%$ & $26.6 \%$ \\
\hline & & Reading and responding to contents & $72.1 \%$ & $4.6 \%$ & $23.3 \%$ \\
\hline
\end{tabular}


more complicated tasks that demanded greater attentional resources. The participants regarded mobile devices as tools for "emergency", "instant searching", and "quick reply". The interview participants frequently mentioned using mobile devices for tasks that were quick and light, such as "checking dictionaries", "surfing on Twitter and Instagram", "posting short passages", "listening to familiar songs with no need to read lyrics", and "watching TED talks that lasted 10 to 20 minutes". However, they often reported using laptops for tasks that were cognitively challenging because they felt "more motivated to challenge [themselves]" and were more likely to concentrate when working on laptops. For instance, one participant explained that she chose to watch the more difficult videos on the laptop because "with [her] current proficiency level, [she had] to listen very attentively in order to understand $80 \%$ of the content". The participants also listed the ease of interacting with online resources on laptops as another reason behind using laptops for more cognitively demanding tasks. For instance, one participant explained that the reason she chose to watch Japanese anime and manga on her laptop was that she had to "keep pausing the clips in order to comprehend the anime", but "the unstable connection on mobile devices" made it very difficult to rewind and replay video content. Laptops were also perceived as supporting multi-tasking more. One participant shared that he did "easier tasks such as quick reading or communicating with friends" on his mobile phone, but read "long and difficult articles where [he] needed to check up a lot of words" on the laptop because it was easier to switch between windows to do word referencing while reading on the laptop. Another participant also cited the convenience in multi-tasking on the laptop as a factor that influenced her tool selection for online writing: "when writing short passages, like one or two sentences, I didn't mind using mobile. But when writing long paragraphs, I would use the laptop because there would be more uncertainties and I needed to refer to the dictionary or the web very frequently". As social communication and connection often involved casual reading and short postings, mobile phones were predominantly utilized to support such learning experiences, whereas the participants diverged in their selection of tools when interacting with authentic materials because these materials might vary in length, difficulty level, and learner familiarity, and might be approached by learners for different purposes.

\section{Discussion}

This study examined university language learners' self-directed use of mobile devices for learning beyond the classroom and found that their out-of-class mobile learning experience could be categorized into three dimensions. The three dimensions corresponded in general with the three core features of m-learning conceptualized in Kearney et al.'s (2012) pedagogical framework. However, the specific manifestations of the three dimensions reflected some unique features of language learning in informal learning contexts. The personalization dimension was manifested in two aspects: the flexibility of learning anytime and anywhere, and the provision of immediate assistance to learning and language use. The heightened assistive aspect of mobile use is unique to informal language learning because learners usually do not have immediate access to teacher and peer support when learning and using language in such contexts. The authenticity dimension was manifested mostly in the use of mobile devices to access entertainment materials, such as songs, video clips, and news updates, and learners reported limited engagement in activities in the authenticity dimension. The limited engagement was to do with the technological constraints of mobile 
devices, the tempo-spatial contexts of mobile use, and learners' language proficiency. Similarly, the connectivity dimension in out-of-class mobile language learning was limited in its manifestation: learners used mobile devices more to connect with peer learners, and were reluctant to engage in social networking in the target language. The limited manifestation made us label this dimension as "connectivity", instead of adopting the term "collaboration" in Kearney et al.'s (2012) model, to reflect the specific nature of mobile language learning in the informal learning contexts. The unique specification of this dimension was related to the social and entertainment functions that mobile devices are usually associated with in daily life (White \& Mills, 2014), and the inadequacy of second language(s) in fulfilling the expected social functions of sharing and communication.

So, what could we make of the findings? First of all, the findings suggest that Kearney et al.'s (2012) m-learning framework can be applied to informal learning contexts, but the manifestation of the different dimensions of the framework is discipline- and context-specific. Thus, Kearney et al.'s (2012) model needs to be readapted to categorize learners' mobile learning experiences in the context of mobile language learning in informal contexts. Second, the participants' positive perception and use of mobile devices for personalization concurred with current research findings that learners are more likely to perceive and utilize the affordances of mobile devices to enhance flexibility in learning anytime and anywhere (Dashtestani, 2016; Steel, 2015; Viberg \& Grönlund, 2013). This finding suggests that facilitating anytime-anywhere learning is a key learner-utilized affordance of mobile devices for out-of-class language learning. Educational interventions to augment this dimension of out-of-class mobile learning may focus on strengthening learners' effective use of dictionary-type resources for vocabulary learning (Levy \& Steel, 2015; Steel \& Levy, 2013). Third, the study found that the limited use of mobile devices for authenticity was shaped largely by the constraining features of mobile devices and the circumstances of use that were compounded by learners' language proficiency. The finding suggests that the affordances of mobile devices for enhanced authenticity in informal learning might be more likely to be voluntarily utilized by learners of high proficiency levels as the constraining features of mobile devices and their use (e.g. small subtitles, levels of concentration needed) might not be as detrimental to them as they were to learners with low proficiency levels. Last but not least, the limited use of mobile devices for social connections among the participants contradicted the current research findings on learners' habitual use of mobile devices for social communication in daily life (Kukulska-Hulme et al., 2011; Rahamat et al., 2011). Thus, although mobile devices are technologically fitted to facilitate social communication in informal contexts, the realization of this technological affordance in the language learning context might be constrained by linguistic and socio-contextual factors. It is possible that the limited use of mobile devices for the social connectivity aspect of language learning might be due to cultural differences, as previous studies have identified the potential influence of culture on mobile use (Byrne \& Diem, 2014; Scheid, 2015) and on social media use (Jackson \& Wang, 2013; Kim, Sohn \& Choi, 2011). In particular, Jackson and Wang (2013) found that Chinese undergraduate students used social media less frequently than US peers. However, previous research in other cultural contexts has also found that language learners, even advanced language learners, showed limited use of technology for social connections (Steel, 2012; Trinder, 2016). Thus, educational mediation and interventions are needed to enhance this dimension of mobile learning in the context of foreign language learning. For instance, educators may build induction programs, such as creating informal social communities of learners across classes and across proficiency levels, to help learners build up their confidence in social networking and sharing in the target language in a 
relatively "safe" environment first before encouraging them to venture out to build their social networks in the target language in daily life. Future research may want to explore how to construct effective educational interventions to promote learners' voluntary use of mobile devices to enhance the authenticity and connectivity aspects of language learning beyond the classroom and to investigate how educational interventions may vary in different sociocultural contexts (Hsu, 2013). That being said, the current findings on the differentiated manifestation of mobile use in different dimensions might also be a product of the influence of the nature of technological activities that the teachers engaged the participants in, as previous studies have shown that teachers' in-class use of technological resources may influence learners' self-initiated, selfdirected out-of-class technology use (Fagerlund, 2012; Lai, 2015). Future studies may want to examine the relationship of the types of teacher-initiated technological activities and the nature of students' self-initiated out-of-class mobile use for language learning. Moreover, learners' selected mobile use for different dimensions may also vary across the learning contexts of different languages, as the availability, accessibility, and usability of different technological resources in different languages may differ and the nature of social relationships within the technological spaces and associated with the technological resources may differ as well. For instance, learners of Spanish may find Spanish social networks more readily available and the social interaction in the networks more welcoming and alive than learners of Japanese, and thus are more likely to engage in mobile use in the social connectivity dimension. Future research may delve deeper into the variations of mobile use in different learning contexts.

This study further revealed learners' selective use of technological tools for different dimensions of language learning in informal contexts. The participants reported associating mobile phones with casual learning and simpler tasks and associating laptops with serious learning and more challenging tasks, which concurs with the findings in previous research studies (Ch'ng \& Samsudin, 2013; Jarvis \& Achilleos, 2013; White \& Mills, 2014). Even for the same task, learners may choose different technological tools depending on the difficulty level of, their familiarity with, and their interest in the materials involved, as well as their self-defined purposes of the task. In addition to the characteristics of the tasks, learners' selective use of mobile devices was further found to be influenced by the technological affordances and constraints of mobile devices, and the tempo-spatial circumstances and sociocultural contexts of the use of mobile devices. Kukulska-Hulme (2012) devised a conceptual framework for planning and designing mobile-supported language learning in informal settings, in which he highlighted that, when designing mobile learning tasks, teachers need to match three dimensions of the tasks, namely the characteristics of the tasks, the time, and the place. The findings from this study suggest one more dimension, namely the technological affordances and constraints of mobile devices and their normal circumstances of use in daily life, to be added to the design framework in the context of voluntary informal language learning. Furthermore, the characteristics of technological tools, time, space, and the activity, and the matching thereof, are relative across learners and should not be defined in a generic sense. Thus, learner characteristics (e.g. interest, proficiency level, age groups, etc.) should be a core consideration and the starting point in defining and mapping the four dimensions of autonomous mobile language learning beyond the classroom. All these technological, linguistic, and contextual factors need to be taken into consideration when designing and promoting mobile language learning beyond the classroom. Future research may tap into the interaction of learner characteristics and the design and self-construction of mobilesupported language learning experience beyond the classroom. 


\section{Conclusion}

This study examined a group of university foreign language learners' self-directed use of mobile devices for language learning beyond the classroom. It identified three dimensions of language learning in informal contexts with mobile devices - personalization, authenticity, and connectivity - and found that this group of learners perceived and voluntarily used mobile devices more to support personalized learning than to enhance the authenticity and social connection in language learning beyond the classroom. They used technological devices selectively for the different dimensions, and the selective use was influenced by the affordances of the devices, learners' culturally informed and habitual use of the devices, and their perceptions of the tempo-spatial circumstances and the nature of the tasks. The findings suggest that learners' voluntary use of mobile devices need to be supported to be more diversified, and that the design of educational interventions that promote mobile learning beyond the classroom and the design of mobile learning activities need to take these factors into consideration.

This study has a few limitations. The study was conducted in the foreign language learning contexts with more than $60 \%$ of the participants being at the beginning proficiency level. The findings might be biased by the particularities of the student population. It is possible that student populations in the second language learning contexts might show different profiles in the use of mobile devices for authentic, situated learning and for social sharing and communication in the target language (Li, Snow \& White, 2015; Ma, 2016). And student populations with higher levels of proficiency might show a greater level of voluntary use of mobile devices to enhance authenticity in learning. Moreover, the majority of the student population was female, which might have elevated the finding on the use of mobile devices for anytime-anywhere learning, as Ch'ng and Samsudin (2013) found that the female students in their study exhibited greater use of mobile devices for ubiquitous learning. Moreover, the study was conducted in the context of Hong Kong, and it is possible that students from different cultural backgrounds and from countries with different mobile infrastructure might show different profiles of mobile learning. Previous research suggests that cultural values may influence learners' perception and use of mobile learning (Hsu, 2013; Viberg \& Grönlund, 2013), and social rules and conventions may define the acceptable and preferred selection and use of technological tools and mobile practices (KukulskaHumle et al., 2011; Sharples, Taylor \& Vavoula, 2007). Future research may want to examine self-directed mobile language learning beyond the classroom in different sociocultural contexts.

\section{References}

Bachmair, B. and Pachler, N. (2014) A cultural ecological frame for mobility and learning. MedienPädagogik: Zeitschrift für Theorie und Praxis der Medienbildung, 24: 53-74.

Bradley, L., Lindström, N. B. and Hashemi, S. S. (2017) Integration and language learning of newly arrived migrants using mobile technology. Journal of Interactive Media in Education, 2017(1): 1-9. https://doi.org/10.5334/jime.434

Burston, J. (2014a) MALL: The pedagogical challenges. Computer Assisted Language Learning, 27(4): 344-357. https://doi.org/10.1080/09588221.2014.914539

Burston, J. (2014b) The reality of MALL: Still on the fringes. CALICO Journal, 31(1): 103-125. https://doi.org/10.11139/cj.31.1.103-125

Burston, J. (2015) Twenty years of MALL project implementation: A meta-analysis of learning outcomes. ReCALL, 27(1): 4-20. https://doi.org/10.1017/S0958344014000159

Byrne, J. and Diem, R. (2014) Profiling mobile English language learners. JALT CALL Journal, 10(1): 3-19. 
Castrillo, M. D., Martín Monje, E. and Bárcena, E. (2014) New forms of negotiating meaning on the move: The use of mobile-based chatting for foreign language distance learning. IADIS. International Journal on WWW/Internet, 12(2): 51-67.

Chen, X.-B. (2013) Tablets for informal language learning: Student usage and attitudes. Language Learning \& Technology, 17(1): 20-36.

Ch'ng, L. K. and Samsudin, Z. (2013) Integration of mobile devices into ubiquitous learning by the 21 st century teenagers. Education, 3(6): 362-374. https://doi.org/10.5923/j.edu.20130306.12

Dashtestani, R. (2016) Moving bravely towards mobile learning: Iranian students' use of mobile devices for learning English as a foreign language. Computer Assisted Language Learning, 29(4): 815-832. https://doi.org/10.1080/09588221.2015.1069360

Demouy, V., Jones, A., Kan, Q., Kukulska-Hulme, A. and Eardley, A. (2016) Why and how do distance learners use mobile devices for language learning? The EUROCALL Review, 24(1): 10-24. https://doi.org/10.4995/eurocall.2016.5663

Duman, G., Orhon, G. and Gedik, N. (2015) Research trends in mobile assisted language learning from 2000 to 2012. ReCALL, 27(2): 197-216. https://doi.org/10.1017/S0958344014000287

Fagerlund, T. (2012) Learning and using English and Swedish beyond the classroom: Activity systems of six upper secondary school students. University of Jyväskylä, Finland, unpublished master's thesis.

Hair, J. F., Tatham, R. L., Anderson, R. E. and Black, W. (1998) Multivariate Data Analysis (5th ed). Upper Saddle River: Prentice-Hall International.

Hong Kong Census and Statistics Department (2016) Thematic Household Survey Report No. 59. Hong Kong.

Hong Kong Computer Society (2013) Survey results on smartphone using and consumption habit of HK students. http://www.hkcs.org.hk/en_hk/misc/press_release/20131104_1_eng.pdf

Hsu, L. (2013) English as a foreign language learners' perception of mobile assisted language learning: A cross-national study. Computer Assisted Language Learning, 26(3): 197-213. https://doi.org/10.1080/09588221.2011.649485

Jackson, L. A. and Wang, J.-L. (2013) Cultural differences in social networking site use: A comparative study of China and the United States. Computers in Human Behavior, 29(3): 910-921. https://doi.org/10.1016/j.chb.2012.11.024

Jarvis, H. A., and Achilleos, M (2013) From computer assisted language learning (CALL) to mobile assisted language use, Tesl-Ej, 16(4): 1-18.

Jones, A. (2015) Mobile Informal Language Learning: Exploring Welsh Learners' Practices. eLearning Papers, 45, 4-14.

Kearney, M., Schuck, S., Burden, K. and Aubusson, P. (2012) Viewing mobile learning from a pedagogical perspective. Research in Learning Technology, 20(1): 1-17. https://doi.org/10.3402/ rlt.v20i0.14406

Kim, J., Ilon, L. and Altmann, J. (2013) Adapting smartphones as learning technology in a Korean university. Journal of Integrated Design \& Process Science, 17(1): 5-16.

Kim, Y., Sohn, D. and Choi, S. M. (2011) Cultural difference in motivations for using social network sites: A comparative study of American and Korean college students. Computers in Human Behavior, 27(1): 365-372. https://doi.org/10.1016/j.chb.2010.08.015

Kukulska-Hulme, A. (2012) Language learning defined by time and place: A framework for next generation designs. In Díaz-Vera, J. E. (ed.), Left to my own devices: Learner autonomy and mobileassisted language learning (Innovation and leadership in English language teaching, Volume 6). Bingley, UK: Emerald Group, 1-13.

Kukulska-Hulme, A. (2016) Mobile assistance in language learning: A critical appraisal. In Palalas, A. and Ally, M. (eds.), The international handbook of mobile-assisted language learning. Beijing: China Central Radio \& TV University Press, 138-160. 
Kukulska-Hulme, A. and de los Arcos, B. (2011) Researching emergent practice among mobile language learners. In 10th World Conference on Mobile and Contextual Learning: mLearn 2011 Conference Proceedings. Beijing: Beijing Normal University, 74-77.

Kukulska-Hulme, A., Gaved, M., Jones, A., Norris, L. and Peasgood, A. (2017) Mobile language learning experiences for migrants beyond the classroom. In Beacco, J.-C., Krumm, H.-J., Little, D. and Thalgott, P. (eds.), The linguistic integration of adult migrants: Some lessons from research. Berlin: De Gruyter, 219-224. https://doi.org/10.1515/9783110477498-030

Kukulska-Hulme, A., Pettit, J., Bradley, L., Carvalho, A. A., Herrington, A., Kennedy, D. M. and Walker, A. (2011) Mature students using mobile devices in life and learning. International Journal of Mobile and Blended Learning, 3(1): 18-52. https://doi.org/10.4018/jmbl.2011010102

Kukulska-Hulme, A. and Sharples, M. (2016) Waypoints along learning journeys in a mobile world. In Ng, W. and Cumming, T. M. (eds.), Sustaining mobile learning: Theory, research and practice. Abingdon: Routledge, 43-56.

Lai, C. (2015) Modeling teachers' influence on learners' self-directed use of technology for language learning outside the classroom. Computers \& Education, 82: 74-83. https://doi.org/10.1016/ j.compedu.2014.11.005

Levy, M. and Steel, C. (2015) Language learner perspectives on the functionality and use of electronic language dictionaries. ReCALL, 27(2): 177-196. https://doi.org/10.1017/S0958344 01400038X

Li, J., Snow, C. and White, C. (2015) Urban adolescent students and technology: Access, use and interest in learning language and literacy. Innovation in Language Learning and Teaching, 9(2): 143-162. https://doi.org/10.1080/17501229.2014.882929

Liu, G.-Z., Kuo, F.-R., Shi, Y.-R. and Chen, Y.-W. (2015) Dedicated design and usability of a contextaware ubiquitous learning environment for developing receptive language skills: A case study. International Journal of Mobile Learning and Organisation, 9(1): 49-65. https://doi.org/10.1504/ IJMLO.2015.069717

Ma, Q. (2016) An evidenced-based study of Hong Kong university students' mobile-assisted language learning (MALL) experience. In Gimeno-Sanz, A., Levy, M., Blin, F. and Barr, D. (eds.), WorldCALL: Sustainability and computer-assisted language learning. New York: Bloomsbury, 211-229.

Petersen, S. A., Procter-Legg, E. and Cacchione, A. (2014) LingoBee: Engaging mobile language learners through crowd-sourcing. International Journal of Mobile and Blended Learning, 6(2): 58-73. https://doi.org/10.4018/ijmbl.2014040105

Pollara, P. and Kee Broussard, K. (2011) Student perceptions of mobile learning: A review of current research. In Koehler, M. \& Mishra, P. (eds.), Proceedings of the Society for Information Technology \& Teacher Education International Conference 2011. Chesapeake, VA: AACE, 1643-1650.

Rahamat, R. B., Shah, P. M., Din, R. B. and Aziz, J. B. A. (2011) Students' readiness and perceptions towards using mobile technologies for learning the English language literature component. The English Teacher, XL, 69-84.

Read, T., Bárcena, E. and Kukulska-Hulme, A. (2016) Exploring the application of a conceptual framework in a social MALL app. In Pareja-Lora, A., Calle-Martínez, C. and Rodriguez-Arancón, P. (eds.), New perspectives on teaching and working with languages in the digital era. Dublin: Research-publishing.net, 223-232. https://doi.org/10.14705/rpnet.2016.tislid2014.436

Saldaña, J. (2016) The coding manual for qualitative researchers (3rd ed.). London: Sage.

Scheid, S. (2015) Cultural and Personal Factors Affecting Mobile Language Learning: An Investigative Approach. Master Thesis. Finland: University of Tampere.

Sharples, M. and Pea, R. (2014) Mobile learning. In Sawyer, R. K. (ed.), The Cambridge handbook of the learning sciences (2nd ed.). New York: Cambridge University Press, 501-521. https://doi.org/ 10.1017/CBO9781139519526.030 
Sharples, M., Taylor, J. and Vavoula, G. (2007) A theory of learning for the mobile age. In Andrews, R. and Haythornthwaite, C. (eds.), The Sage handbook of e-learning research. London: Sage, 221-247. https://doi.org/10.4135/9781848607859.n10

Steel, C. (2012) Fitting learning into life: Language students' perspectives on benefits of using mobile apps. In Brown, M., Hartnett, M. and Stewart, T. (eds.), Ascilite 2012: Future challenges, sustainable futures: Proceedings. Wellington, New Zealand: Massey University, 875-880.

Steel, C. (2015) Students' perspectives on the affordances and constraints of using mobile devices and applications for learning languages. In Gimeno-Sanz, A., Levy, M., Blin, F. and Barr, D. (eds.), WorldCALL: Sustainability and computer-assisted language learning. New York: Bloomsbury, 230-243.

Steel, C. H. and Levy, M. (2013) Language students and their technologies: Charting the evolution 2006-2011. ReCALL, 25(3): 306-320. https://doi.org/10.1017/S0958344013000128

Stevens, J. (1992) Applied multivariate statistics for the social sciences (2nd ed.). Hillsdale, NJ: Erlbaum.

Stockwell, G. (2008) Investigating learner preparedness for and usage patterns of mobile learning. ReCALL, 20(3): 253-270. https://doi.org/10.1017/S0958344008000232

Stockwell, G. (2010) Using mobile phones for vocabulary activities: Examining the effect of the platform. Language Learning \& Technology, 14(2): 95-110.

Stockwell, G. (2013) Tracking learner usage of mobile phones for language learning outside of the classroom. CALICO Journal, 30: 118-136.

Stockwell, G. and Hubbard, P. (2013) Some emerging principles for mobile-assisted language learning. Monterey, CA: The International Research Foundation for English Language Education.

Sung, Y.-T., Chang, K.-E. and Liu, T.-C. (2016) The effects of integrating mobile devices with teaching and learning on students' learning performance: A meta-analysis and research synthesis. Computers \& Education, 94: 252-275. https://doi.org/10.1016/j.compedu.2015.11.008

Sung, Y.-T., Chang, K.-E. and Yang, J.-M. (2015) How effective are mobile devices for language learning? A meta-analysis. Educational Research Review, 16: 68-84. https://doi.org/10.1016/ j.edurev.2015.09.001

Trinder, R. (2016) Blending technology and face-to-face: Advanced students' choices. ReCALL, 28(1): 83-102. https://doi.org/10.1017/S0958344015000166

Underwood, J., Luckin, R. and Winters, N. (2014) MALL in the wild: Learners' designs for scaffolding vocabulary learning trajectories. In Jager, S., Bradley, L., Meima, E. J. \& Thouësny, S. (eds.), CALL design: Principles and practice - Proceedings of the 2014 EUROCALL Conference, Groningen, the Netherlands. Dublin: Research-publishing.net, 391-397. https://doi.org/10.14705/ rpnet.2014.000251

Viberg, O. and Grönlund, Å. (2013) Cross-cultural analysis of users' attitudes toward the use of mobile devices in second and foreign language learning in higher education: A case from Sweden and China. Computers \& Education, 69: 169-180. https://doi.org/10.1016/j.compedu.2013.07.014

Wang, S. and Smith, S. (2013) Reading and grammar learning through mobile phones. Language Learning \& Technology, 17(3): 117-134.

Waragai, I., Raindl, M., Ohta, T. and Miyasaka, K. (2016) Mobile assisted language learning and mnemonic mapping - The loci method revisited. In Papadima-Sophocleous, S., Bradley, L. and Thouësny, S. (eds.), CALL communities and culture - Short papers from EUROCALL 2016. Dublin: Research-publishing.net, 462-467. https://doi.org/10.14705/rpnet.2016.eurocall2016.607

Wong, L.-H., Milrad, M. and Specht, M. (2015) Seamless learning in the age of mobile connectivity. Singapore: Springer. https://doi.org/10.1007/978-981-287-113-8

White, J. and Mills, D. J. (2014) Examining attitudes towards and usage of smartphone technology among Japanese university students studying EFL. CALL-EJ, 15(2): 1-15. 


\begin{abstract}
About the authors
Chun Lai is an Associate Professor at the Faculty of Education, the University of Hong Kong. Her research interests include self-directed learning beyond the classroom and technology-enhanced language learning.

Dongping Zheng is an Associate Professor in the Department of Second Language Studies at the University of Hawaii at Mānoa. She studies how technology can alter and augment language learning processes in place-based environments. She has published a dozen papers on the topics of affordances of virtual worlds, video games, and mobile devices for crosscultural communication and education. She is also interested in Chinese philosophy, namely Confucian role ethics and Daoism/Taoism. Her recent work has been focusing on finding common ground between these correlative cosmological perspectives and Cartesian reductionist approaches for building a culturally balanced educational model and research methodology.
\end{abstract}

